\title{
Effect of Toluene and Dioctylphthalate on the Rebar Corrosion of Medium Carbon Steel in Seawater and Cassava Fluid
}

\author{
Mohammed Adamu ${ }^{1 *}$, Lasisi Ejibunu Umoru ${ }^{2}$, Oladeji Oluremi Ige ${ }^{2}$ \\ ${ }^{1}$ Department of Metallurgical Engineering, Kogi State Polytechnic, Lokoja, Nigeria \\ ${ }^{2}$ Department of Materials Science and Engineering, Obafemi Awolowo University, Ile-Ife, Nigeria \\ Email: "
}

Received September 3, 2013; revised October 20, 2013; accepted November 5, 2013

Copyright (C) 2014 Mohammed Adamu et al. This is an open access article distributed under the Creative Commons Attribution License, which permits unrestricted use, distribution, and reproduction in any medium, provided the original work is properly cited. In accordance of the Creative Commons Attribution License all Copyrights (C) 2014 are reserved for SCIRP and the owner of the intellectual property Mohammed Adamu et al. All Copyright (C) 2014 are guarded by law and by SCIRP as a guardian.

\section{ABSTRACT}

Chemical mitigation is regularly used as one of the principal prevention and control techniques in reinforcement corrosion. Hence this study presents the effect of toluene and dioctylphthalate on the rebar corrosion of medium carbon steel in seawater and cassava fluid with a view to determining inhibitive potentials of the different inhibitors in the two media. Gravimetric and voltametric techniques were employed in this study and a total of forty-five corrosion coupons of different dimensions were produced. Forty coupons were used for gravimetry and the remaining five for corrosion potentials measurements. Eight of the samples were used as control; while other eight samples were admixed with dioctylphthalate and toluene in concrete cubes. It was later immersed in seawater and cassava fluid for a total duration of 32 days and the measurements were taken at interval of $\mathbf{4}$ days in order to determine the corrosion rates in mils per year (mmpy). Two controls and admixed samples were later immersed in seawater and cassava fluid, respectively, for durations of thirty-two days to determine the corrosion potentials using a voltmeter and a Copper-Copper Sulphate Electrode $\left(\mathrm{Cu} / \mathrm{CuSO}_{4}\right)$. The $\mathrm{pH}$ of each medium was also measured throughout the period of exposure. The results obtained showed that all the samples except the control samples, displayed some degree of inhibition. The inhibition levels for the admixed samples in seawater were on the higher side compared with those in cassava fluid. The inhibition efficiencies for different inhibitors followed different trends in different environment. The inhibition efficiencies for toluene in cassava fluid and seawater were $21.64 \%$ and $45.78 \%$ respectively. The study concluded that organic inhibitors were effective in inhibiting corrosion in cyanide and chloride contaminated concrete cubes.

\section{KEYWORDS}

Inhibitor; Rebar Corrosion; Steel; Seawater; Cassava Fluid

\section{Introduction}

Corrosion phenomenon is exhibited by most engineering materials in nearly all environments. The corrosion of steel reinforcing bars is a major problem because of deicing salts in highway bridges, etc. [1]. Reinforcing steels in concrete suffer from corrosion that is usually induced by insufficient level of alkalinity and the presence of aggressive ions such as $\mathrm{Cl}^{-}, \mathrm{SO}_{4}^{2-}$, etc., as well as concrete exposures to external hostile environments. About $60 \%$

"Corresponding author. of the major failure of concrete structures can be traced to the above causes [2]. Concrete surfaces are often characterized by micro-cracks and micro pores that provide a path for the transport of aggressive ions. The corrosion of reinforcing steel therefore depends on the rate of diffusion of ions such as chlorides, and carbon dioxide gas, $\mathrm{CO}_{2}$.

The concrete structures usually have within them a highly alkaline condition (pH 12.5 - 13.5) that is said to be responsible for the formation of passive oxide films on the steel surface [3]. The oxide film forms a physical 
barrier to the movement of moisture, oxygen and aggressive ions and consequently protects the steel from further corrosion. With a lowering of the $\mathrm{pH}$ value to and below 11 , the passive oxide layer suffers degradation which ultimately leads to the corrosion of the base steel bar. The carbonation reaction in the concrete as well as the penetration of chloride ions usually results in acidification and consequent decreases in the alkalinity of the structures [4].

Cassava (Manihot utilissima) is an agricultural product that has found extensive application in the starch and food industry all over the world. In its processing however, one of the factors that have impeded its exploitation is the frequency with which the processing machines break down due to corrosion of competent parts resulting from contact with the cassava juice, which contains 6 10 per cent cyanic acid [5]. This issue has resulted in increasing interest in research into the environment/metal interface reactions and the means of reducing the damaging effects of corrosion on metals and alloys.

Chemical inhibitors can be effective in this type of application. The use of various substances as inhibitors to help mitigate the corrosive environment is an important means of reducing damage. Inhibition is generally more attractive in closed or recirculated systems where the cumulative cost of inhibitor additions should be low. Inhibitors are effective as a result of their controlling influence on the cathode- or anode-areas of reactions [6]. Typical examples of inhibitors used for minimizing corrosion of iron and steel in aqueous solutions are the chromates, phosphates and silicates. These ions minimize corrosion by increasing anodic polarization and are called "anodic inhibitors". Organic and inorganic sulphates, sulphides and amines frequently are used in minimizing corrosion of iron and steel in acid solutions. In this instance, they control cathodic polarization and are "cathodic inhibitors". For example, the addition of copper sulphate to dilute $\mathrm{H}_{2} \mathrm{SO}_{4}$ stops the corrosion of stainless steels in hot dilute solutions of this acid, whereas the uninhibited acid causes rapid corrosion [7]. However, for food processing, the interest in using organic compounds as inhibitors is beginning to be recognized, due mainly to their inherent and non-toxic nature. The cassava processing industry today is facing many corrosion problems with the materials of construction of their machinery, much of which is fabricated from carbon steel. The problem is traceable to the aggressive nature of the cyanide content of cassava. The results of this study therefore are expected to proffer a possible solution to excessive corrosion damage experienced by the cassava processing industry. Corrosion inhibitor is a substance which when added in small concentrations to an environment decreases the corrosion rate considerably. To be fully effective all inhibitors require being present above a certain minimum concentration $[8,9]$.

Inhibitors are chemicals that react with a metallic surface, or the environment this surface is exposed to, giving the surface a certain level of protection. Inhibitors often work by adsorbing themselves on the metallic surface, protecting the metallic surface by forming a film. Most commonly, corrosion inhibitors are classified as anodic, cathodic or mixed according to their influence on the electrochemical reaction involving metal, and their environment $[10,11]$. Corrosion inhibitors have been in use for several decades and the most familiar examples of their applications are in paints and coatings on metals where nitrate, chromate, phosphate, benzoates, borates and oxides are incorporated, Nitrite is being used as inhibition admixture in concrete reinforcement [12-15]. It is well established that inhibitors function in one or more ways to control corrosion: by adsorption of a thin film onto the surface of a corroding material, by inducing the formation of a thick corrosion product, or by changing the characteristics of the environment resulting in reduced aggressiveness [16].

Most metals are inherently unstable and have the natural tendency to react with their environments to obtain lower energy by forming a chemical compound in a more stable state. Steel materials which are very susceptible to attack in aggressive media are the commonly exposed metals in industrial environments [17]. One of the serious concerns to the durability of reinforced concrete is chloride-induced corrosion of reinforcing steel, which leads to a subsequent loss in the strength, serviceability, and aesthetics of the structure.

Corrosion of reinforcing steel in concrete is brought about mainly by two factors. Firstly, it is due to the ingress of atmospheric carbon dioxide to the steel-concrete interface, and secondly, and more importantly, due to the diffusion of the chloride ions. Field studies conducted at King Fahd University of Petroleum and Minerals [18] indicated that the presence of excessive chloride concentrations in the deteriorated concrete structure is the main cause of reinforcement corrosion. The chloride ions were reported to be contributed by either the mix constituents or those entering the concrete from the external environment. The concomitant presence of sulphate salts with the chloride ions is known to aggravate the corrosive attack on reinforcing steel $[19,20]$. The use of corrosion inhibitors for new structures, also known as corrosion inhibiting admixtures (CIAs), seems to be a promising strategy in controlling steel corrosion in concrete.

The focus of this research is to investigate the inhibitive potential of toluene and dioctylphthalate (DOP) on the rebar corrosion of medium carbon steel in seawater and cassava fluid. There are lots of restriction to the deployment of these inhibitors due to several rules and regulations advocated by numerous governmental orga- 
nizations. However the scope of this work is to use these inhibitors in very small quantity which are within the range provided by the regulatory bodies and to use them in safe environments. The maximum concentrations of the inhibitors are less than $100 \mathrm{ppm}$ as advocated by OSHA. The environments obtainable in concrete industry have adequate ventilation and aeration which makes them be safe coupled with the expected high inhibition efficiency. Hence this study investigates the effect of toluene and DOP on corrosion associated with concrete industry.

\section{Experimental Details}

\subsection{Materials}

Medium carbon steel was sourced commercially for this research work. Table 1 is the result of the chemical composition analysis carried out spectrometrically at Grand Foundry, Lagos, Nigeria. Crushed limestone with maximum size of $6.25 \mathrm{~mm}$ from Zerock quarry, lokoja was used as coarse aggregate. While the fine aggregate was sand dunes obtained from Obafemi Awolowo University, Ile-Ife, Nigeria with specific gravity of 2.64 and average absorption of $0.57 \%$. Dangote Portland cement was used in all the concrete mix. Seawater from bar-beach, Lagos and Cassava fluid freshly obtained from grated and squeezed cassava tubers at the Obafemi Awolowo University Farm Settlement, Ile-Ife served as the research environments.

A pH meter (model $\mathrm{pH} 2603$ ) and an impedance voltmeter (model DT9205A) were used to determine the $\mathrm{pH}$ of the environments and the corrosion potentials. The total duration of the corrosion experiments were 32 days and the measurements were taken at an interval of 4 days. The two organic inhibitors (toluene and dioctylphthalate) were commercially obtained for the purpose of this research and the volume was kept constant at $45 \mathrm{ml}$.

\subsection{Preparation of Concrete-Cubes}

Concrete-cubes, $90 \times 50 \times 120 \mathrm{~mm}$ and $50 \times 15 \times 45 \mathrm{~mm}$ reinforced with $8 \mathrm{~mm}$ diameter medium carbon steel embedded at the centre were used for the corrosion studies. They had an effective cover of $50 \mathrm{~mm}$ and $15 \mathrm{~mm}$ at the bottom, respectively. A total of 90 concrete-cubes of different dimensions were cast to assess the effectiveness of inhibitors in retarding reinforcement corrosion. The mix ingredients in this case were Portland cement, aggregate, water, and salt as shown in Table 2. The concrete com- position ratio (1:2:3 for cement: sand: gravel) was done according to Popovics (1998). Concrete constituents were mixed in a mixing pan for approximately 3 to 5 minutes until a uniform mixture was achieved. The moulds were filled with concrete in approximately three equal layers and vibrated for consolidation using physical effort. The inhibitors were added to the mixes by dissolving them in the mixing water. The concrete-cubes were performed on a single day for each of two batches of eight in a given set.

Therefore, all concrete-cubes containing a given inhibitor treatment are the same age and subsequently tested at the same time.

\subsection{Curing of the Concrete-Cubes}

After casting, the specimens were covered with wet burlap for 12 hours. Thereafter, they were cured by covering them with wet burlap and plastic sheets for one week. The burlaps were wetted twice daily. Following the curing period, the specimens were exposed to different exposure conditions.

\subsection{Electrode Potentials Measurements}

Reinforcement corrosion was monitored by measuring the corrosion potentials using a Copper/Copper Sulphate electrode and a high impedance voltmeter (model DT9205A). These measurements provide qualitative information on the state of passivity of reinforcing steel [22]. Weight loss measurements were taken at intervals of 96 hours for 32 days period of exposure using a chemical weighing balance (model FA2104A).

\subsection{Gravimetric Measurements}

The rebar corrosion-cubes were immersed in seawater and cassava fluid, respectively, for an interval of 4 days each. After the 4 days period, a corrosion-cube was removed, the concrete-cube opened, the rebar sample cleaned thoroughly then weighed using a weighing balance.

The corrosion rate of each sample was determined and calculated using the relation:

$$
R=\frac{534 W}{D A T}
$$

where $R$ is corrosion rate (mpy); $\mathrm{W}$ is weight loss of samples (mg); $A$ is area of samples $\left(\right.$ in $\left.^{2}\right) ; T$ is exposure time (hr.) and $D$ is density of medium carbon steel $\left(\mathrm{g} / \mathrm{cm}^{3}\right)$

Table 1. Chemical Composition (wt. \%) of experimental medium carbon steel.

\begin{tabular}{|c|c|c|c|c|c|c|c|c|c|c|}
\hline Element & $\mathrm{C}$ & $\mathrm{Si}$ & $\mathrm{Mn}$ & $\mathrm{P}$ & $\mathrm{S}$ & Co & Mo & $\mathrm{Ni}$ & $\mathrm{Cu}$ & $\mathrm{Fe}$ \\
\hline wt. \% & 0.347 & 0.214 & 0.590 & 0.037 & 0.043 & 0.0052 & 0.0083 & 0.119 & 0.229 & 98.20 \\
\hline
\end{tabular}


[23].

The inhibitor efficiency $(P)$ in seawater and cassava fluid was determined from the relationship:

$$
P=100 \frac{\left(W_{1}-W_{2}\right)}{W_{1}}
$$

where $P$ is the Inhibition Efficiency (\%), $W_{1}, W_{2}$ are the corrosion rates in the absence and presence of the inhibitors, respectively.

\section{Results and Discussion}

\subsection{Corrosion Rate Measurements}

\subsubsection{Uninhibited Samples}

Figure 1 shows the corrosion rates of the uninhibited samples in seawater and cassava fluid environments. It was observed from the graph that samples immersed in cassava fluid exhibited severe corrosion rates as compared with samples in seawater. This could be as a result of the presence of cyanide ion $\left(\mathrm{CN}^{-}\right)$in cassava fluid which is more aggressive compared with chloride ion $\left(\mathrm{Cl}^{-}\right)$found in seawater. The presence of carbohydrates and fats in cassava extract [24] are contributing factors for the corrosion of these metals. These constituents are sources of oxygen which may increase the oxidation process in the medium thus promoting corrosion of the materials. One of the most aggressive ions in cassava fluid is the cyanide ion $\left(\mathrm{CN}^{-}\right)$.

The behaviour of this group is analogous to that of the halogens in that it forms hydrocyanic acid, HCN, which is a very weak acid. Cyanogen and cyanate are easily reduced to form $\mathrm{HCN}$ and $\mathrm{CN}^{-}$, respectively, in accordance with Equations (3) and (4) [25]:

Table 2. Batch composition of concrete mix [21].

\begin{tabular}{cccccc}
\hline Materials & Water & Cement & Piedmont Gravel & Sand & Salt \\
\hline Weight (Kg) & 1.97 & 4.2 & 12.6 & 8.4 & 0.30 \\
\hline
\end{tabular}

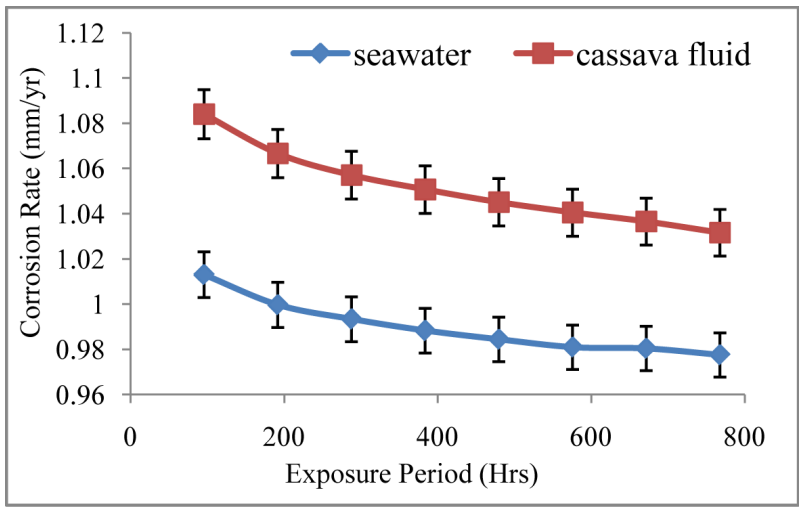

Figure 1. The corrosion rate of the uninhibited samples in seawater and cassava fluid environments.

$$
\begin{gathered}
\frac{1}{2} \mathrm{C}_{2} \mathrm{~N}_{2}+\mathrm{H}^{+}+\mathrm{e}^{-}=\mathrm{HCN} \\
\mathrm{OCN}^{-}+2 \mathrm{H}^{+}+2 \mathrm{e}^{-}=\mathrm{CN}^{-}+\mathrm{H}_{2} \mathrm{O}
\end{gathered}
$$

When steel is immersed in cassava solution, corrosion commences with iron as the anode experiencing dissolution according to the reaction:

$$
\mathrm{Fe}=\mathrm{Fe}^{2+}+2 \mathrm{e}^{-}
$$

At the cathode, ionization of HCN occurs as follows [26]:

$$
\mathrm{HCN}=\mathrm{CN}^{-}+\mathrm{H}^{+}
$$

The overall reaction according to the anode and the cathode reactions can be given as:

$$
\mathrm{Fe}^{2+}+2 \mathrm{CN}^{-}+2 \mathrm{H}^{+}=\mathrm{Fe}(\mathrm{CN})_{2}+\mathrm{H}_{2}
$$

From the foregoing, it is understood that under a damp condition, a highly alkaline medium is brought about by the hydration of cement paste in concrete to produce calcium hydroxide, which causes iron to passivate. The passivation is described as the formation of gamma- $\mathrm{Fe}_{2} \mathrm{O}_{3}$ and delta ferric oxide. Corrosion in seawater must have been as a result of intrusion of the inherently aggressive chloride ions $\left(\mathrm{Cl}^{-}\right)$, which are capable of destroying the passivating film around the steel reinforcement. A value of $0.5 \mathrm{~kg}$ of chloride per cubic metre of concrete has been accepted as the threshold to start serious corrosion [27].

The degree of corrosion protection provided by the concrete environment was reduced probably when the reinforced structure was immersed in seawater. Chlorides penetrated through the hardened concrete and reach the bar. This resulted in progressive accumulation of rust on the rebar which causes concrete cracking and spalling. Carbon dioxide from the air also penetrates into the concrete, reacts with the cement constituents and reduces its alkalinity.

Seawater contains chloride ions which are reduced to form hydrgen chloride and chloride ion. The decrease in $\mathrm{pH}$ of the concrete environment was as a result of the release of the hydrochloric acid $(\mathrm{HCl})$ as given in the equations below:

Local acidification of electrolyte by the reactions:

$$
\begin{gathered}
2 \mathrm{Fe}+2 \mathrm{Cl}_{2}=2 \mathrm{FeCl} \text { (unstable) } \\
\mathrm{FeCl}_{2}+2 \mathrm{H}_{2} \mathrm{O}=\mathrm{Fe}(\mathrm{OH})_{2}+2 \mathrm{HCl}
\end{gathered}
$$

The $\mathrm{pH}$ variation of the concrete environment with time exposure can be traced to Equations (8) and (9) during which the acidity of the concrete increase. That is, the decrease in the $\mathrm{pH}$ of the concrete was associated with the release of the $\mathrm{HCl}$ above.

With the immersion of the medium carbon steel in 
seawater, it is most probable that corrosion sets in with dissolution of iron at the anode (Equation (10)), dissociation of $\mathrm{HCl}$ (Equation (11)) and consumption of dissolved oxygen and the electrons produced at the anode according to Equation (12).

$$
\begin{gathered}
\mathrm{Fe}=\mathrm{Fe}^{2+}+2 \mathrm{e}^{-} \\
\mathrm{HCl}=\mathrm{CN}^{-}+\mathrm{H}^{+} \\
\mathrm{O}_{2}+\mathrm{H}_{2} \mathrm{O}+4 \mathrm{e}^{-}=4 \mathrm{OH}^{-}
\end{gathered}
$$

However, as soon as all the chlorides have been consumed and the production of $\mathrm{HCl}$ is halted, the overall reaction is expected to change to those of Equations (13) and (14), respectively, leading to the release of ferrous hydroxide, $\mathrm{Fe}(\mathrm{OH})_{2}$ or in the presence of surplus oxygen, ferric hydroxide, $\mathrm{Fe}(\mathrm{OH})_{3}$ as the corrosion products.

$$
\begin{aligned}
& \mathrm{Fe}^{2+}+2(\mathrm{OH})^{-}=\mathrm{Fe}(\mathrm{OH})_{2} \\
& \mathrm{Fe}^{3+}+3(\mathrm{OH})^{-}=\mathrm{Fe}(\mathrm{OH})_{3}
\end{aligned}
$$

These products are probably responsible for the increase in alkalinity of the concrete medium resulting in subsequent increase in $\mathrm{pH}$. The increased $\mathrm{pH}$ reduces the attacks of the medium carbon steel by the concrete medium. This trend is supported by Pourbaix diagram for iron-water system where $\mathrm{Fe}(\mathrm{OH})_{2}$ and $\mathrm{Fe}(\mathrm{OH})_{3}$ are the product of corrosion in alkaline medium.

\subsubsection{Inhibited Conditions}

Figure 2 depicts the corrosion rates of the uninhibited and inhibited samples in (a) seawater and (b) cassava fluid. It was observed from the figures collected that corrosion rates decreased more with the inhibited samples of rebar as compared to rebar without inhibitor. It shows that organic inhibitors possess inhibitive potentials in the two environments. It was observed that the corrosion rates decreased with the inhibited rebar samples compared to the uninhibited rebar samples. In general, the observation showed that organic inhibitors used effectively inhibited the rebar samples immersed in seawater as compared with the control that has the highest corrosion rates of 1.09 and 1.01 mmpy. Corrosion of metals in acidic medium has been attributed to the presence of water, dissolved oxygen, $\mathrm{O}_{2}$ in air and $\mathrm{H}^{+}$, which accelerate the corrosion process [28]. The corrosion rates of the rebar immersed in cassava fluid is higher than those immersed in seawater. This can be attributed to the fact that cassava fluids have more aggressive ions than seawater. The inhibitive properties of these organic compounds are assumed to be due to the presence of Group VA and VIA elements (nitrogen, sulphur, and oxygen among others). Also the ability of these elements to form multiple bonds in the molecules that facilitate adsorption on the metal surface. The effectiveness of the organic inhibitors

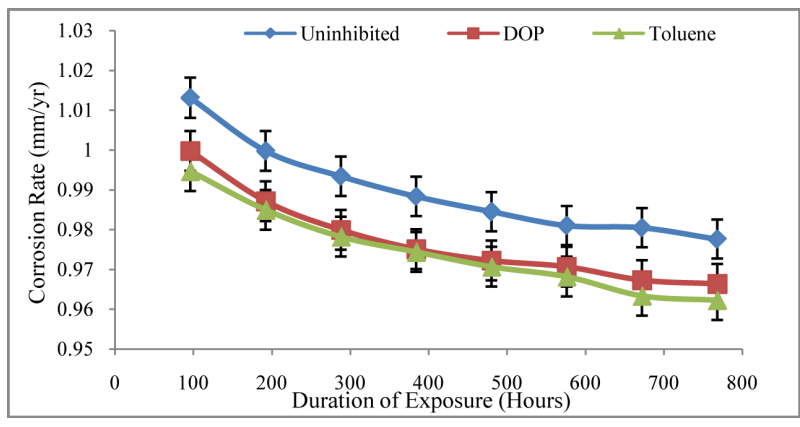

(a)

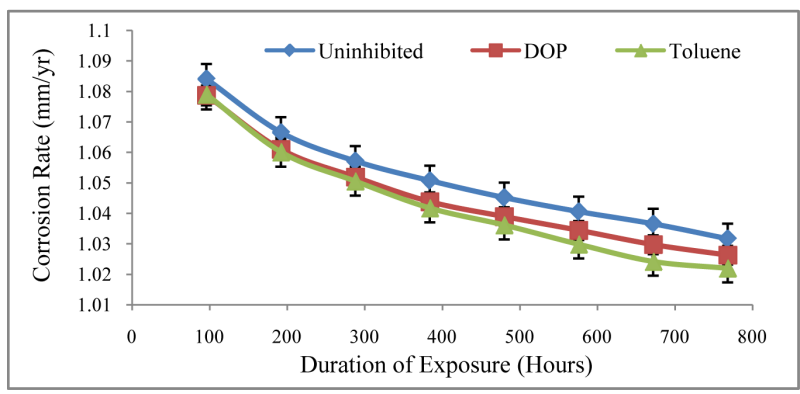

(b)

Figure 2. Corrosion rates of the uninhibited and inhibited samples in (a) seawater and (b) cassava fluid.

mainly depends on some physicochemical properties of the molecule in relation to its functional groups and to the possible steric effects and electronic density of donor atoms. This induced greater adsorption of the inhibitor molecules onto the surface of carbon steel, leading to the formation of a corrosion protecting film. All these facts would have contributed to the effective inhibition of the rebar in the presence of toluene and DOP [29].

\subsection{Electrode Potential Techniques}

The effect of electrode potentials as a function of exposure time for rebar samples in seawater and cassava fluid for inhibited and uninhibited environments is as shown in Figure 3. The tendency of any metal to react with an environment is indicated by the potential it develops in contact with the environment. In reinforced concrete structures, concrete acts, as an electrolyte and the reinforcement will develop a potential depending on the concrete environment, which may vary from place to place. The tendency of any metal to react with an environment is indicated by the potential it develops in contact with the environment. In reinforced concrete structures, concrete acts, as an electrolyte and the reinforcement will develop a potential depending on the concrete environment, which may vary from place to place.

The addition of inhibitors show similar trend that is cassava fluids samples are more anodic than samples in seawater. The electrode potentials for inhibited samples moved in the cathodic direction implying that they are 
cathodic inhibitors. This implies that they will impede the reduction reactions. They have high over potential for hydrogen and they form precipitates at the cathode area [30].

\section{3. pH Measurement}

The $\mathrm{pH}$ values obtained are represented in Figures 4 and 5 for the rebar immersed in seawater and cassava fluid, respectively for uninhibited and inhibited samples. The $\mathrm{pH}$ value for seawater move towards neutral region while

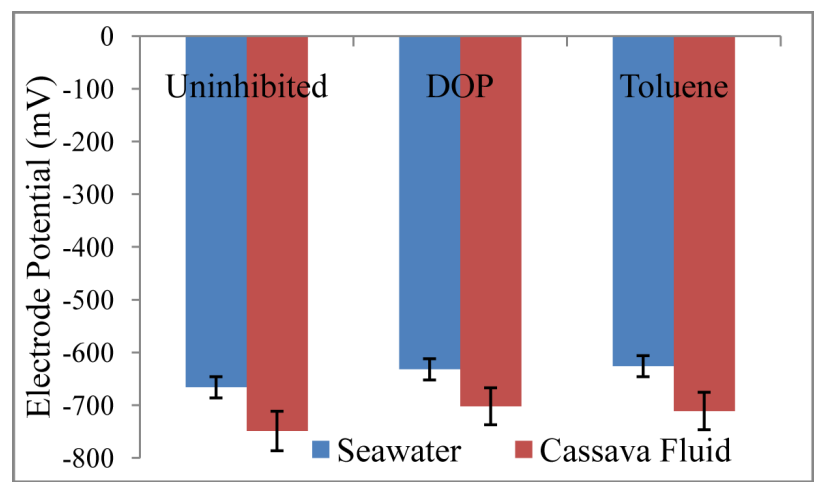

Figure 3. The effect of electrode potential on the uninhibited and inhibited samples in both seawater and cassava fluid environments.

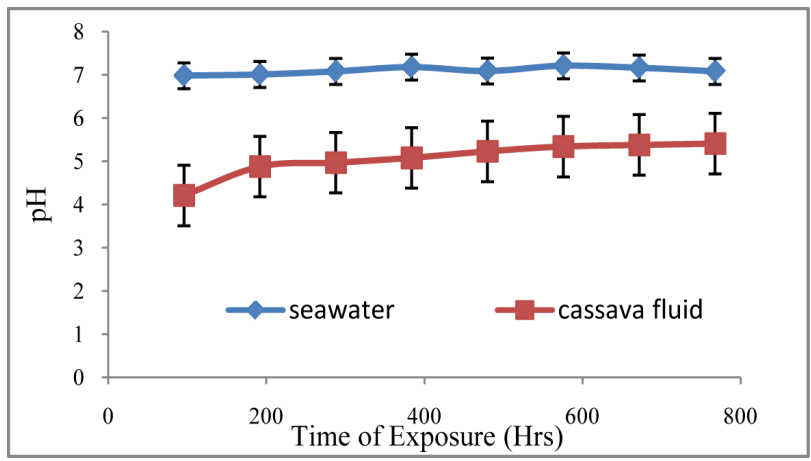

Figure 4. Effect of pH on uninhibited samples in both the seawater and cassava fluid environments.

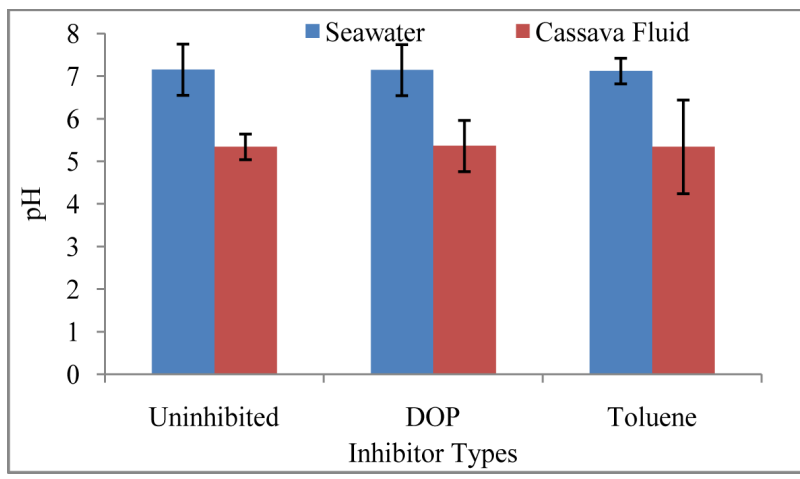

Figure 5. Effect of pH on the uninhibited sample and samples inhibited with different inhibitors.

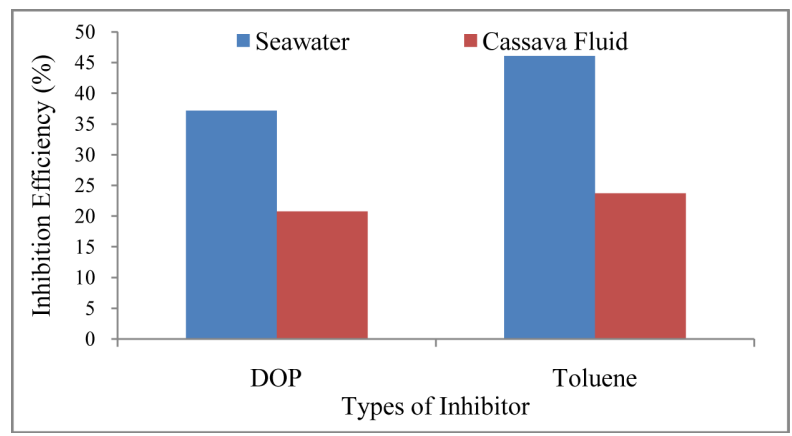

Figure 6. The inhibition efficiency in seawater and cassava fluid environments.

that of cassava medium are in the acidic region. This could account for the low degradation rates as observed for steel immersed in seawater. The alkalinity of the media increased with and without inhibitors. Based on this it can be stated that the organic inhibitors are cathodic precipitators and they precipitates insoluble compounds on the steel surface.

\subsection{Inhibition Efficiencies (\%)}

Figure 6 illustrates the inhibition efficiency (\%) of the organic inhibitors in seawater and cassava fluids. Inhibition efficiency for inhibitors immersed in seawater displayed outright decrease in the efficiency of the inhibitors mostly because the chloride ion $(\mathrm{Cl})$ in the seawater could not arrest the effect of the various inhibitors used whereas, observations from cassava fluid show otherwise. Inhibition efficiency for the various inhibitors immersed in cassava fluid environment displayed early increase in the efficiency of the inhibitors. This can be attributed to the presence of cyanide ion $\left(\mathrm{CN}^{-}\right)$in cassava fluid which is very aggressive.

\section{Conclusions}

On the basis of the strength of results obtained in this investigation, the following conclusions can be drawn:

- The corrosion of carbon steel in seawater and cassava fluid can be inhibited by toluene and dioctylphthalate, to varying degrees.

- The inhibitive potentials of these inhibitors increase with increased concentration but to a peak concentration beyond which inhibition efficiency decreases.

- All the inhibitors were generally effective in retarding the rate of reinforcement corrosion in the chloridecontaminated concrete specimen and the cyanide-contaminated concrete specimen but generally more effective in the seawater environment.

\section{REFERENCES}

[1] M.G. Fontana, “Corrosion Engineering,” 3rd Edition, B 
\& Jo Enterprise Pte Ltd., Singapore, 1988, p. 443.

[2] H. A. Ali, "The Effect of a Waste-Products Mix on Concrete Strength and Protection of Steel Reinforcement in Sulphate Media," Journal of Corrosion Prevention and Control, Vol. 46, No. 3, 1999, p. 76.

[3] M. M. Nasar, "The Effect of Environmental Temperature on the Corrosion of Reinforced Concrete," Journal of Corrosion Prevention and Control, Vol. 44, No. 9, 1997, pp. 167-172.

[4] R. D. Browne, "Mechanisms of Corrosion of Steel in Concrete in Relation to Design, Inspection, Repair of Offshore and Coastal Structures, Performances of Concrete in Marine Environment," American Concrete Institute, Farmington Hills, Sp-65, 1980, p. 169.

[5] V. A. Oyenuga and E. O. Amazigo, “A Note on Hydrocyanic Content of Cassava," West African Journal of Biological Chemistry, Vol. 1, No. 2, 1957, pp. 29-43.

[6] W. H. Ailor, "Handbook on Corrosion Testing and Evaluation,” Wiley, Etobicoke, 1964, pp. 1150-1165.

[7] F. G. Fontana and N. D. Greene, “Corrosion Engineering," McGraw-Hill, New York, 1978, p. 59.

[8] E. H. Norman, "NACE Glossary of Corrosion Terms," Materials Protection, Vol. 4, No. 1, 1965, p. 79.

[9] C. C. Nathan, "Corrosion Inhibitors," National Association of Corrosion Engineers (NACE), Houston, 1973, p. 279.

[10] S. W. Dean Jr., "Inhibitor Type,” Material Performance, Vol. 20, No. 11, 1981, pp. 47-51.

[11] V. S. Ramachandran, "Concrete Admixtures Handbook: Properties, Science and Technology," 5th Edition, Noyes Publications, Park Ridge, New Jersey, 1984, p. 626.

[12] H. Konno, S. K. Obayashi, H. Takahash and M. Nagayama, "The Hydration of Barrier Oxide Films on ions," Corrosion Science, Vol. 10, pp. 913-923.

[13] H. S. Isaacs, S. Virtanen, M. P. Ryan, P. Schmuki and L. J. Oblonsky, "Incorporation of $\mathrm{Cr}$ in the Passive Film on Fe from Chromate Solutions,” Electrochimica Acta, Vol. 47, No. 19, 2002, pp. 3127-3130. http://dx.doi.org/10.1016/S0013-4686(02)00231-1

[14] P. Montes, T. W. Bremner and D. H. Lister, "Influence of Calcium Nitrite Inhibitor and Crack Width on Corrosion of Steel in High Performance Concrete Subjected to a Simulated Marine Environment," Cement and Concrete Composites, Vol. 26, No. 3, 2004, pp. 243-253. http://dx.doi.org/10.1016/S0958-9465(03)00043-X

[15] K. K. Sideris and A. E. Savva, "Durability of Mixtures Containing Calcium Nitrite Based Corrosion Inhibitor," Cement \& Concrete Composites, Vol. 27, No. 2, 2005, pp. 277-287. http://dx.doi.org/10.1016/j.cemconcomp.2004.02.016

[16] N. Hackerrman, "Fundamentals of Inhibitors," NACE Basic Corrosion Course, NACE, Houston, 1965.

[17] S. Craig, "Welding Technology Today Principles and
Practices,” Prentice-Hall, Inc., Upper Saddle River, 1989, p. 301.

[18] D. F. H. Rasheeduzzafar and A. S. Al-Gahtani, "Corrosion of Reinforcement in Concrete Structures in the Middle East," Concrete International: Design and Construction, Vol. 7, No. 9, 1985, pp. 48-55.

[19] O. S. B. Al-Amoudi and M. Maslehuddin, "The Effect of Chloride and Sulphate ions on Reinforcement Corrosion," Cement and Concrete Research, Vol. 23, No. 1, 1993, pp. 139-146. http://dx.doi.org/10.1016/0008-8846(93)90144-X

[20] O. S. B. Al-Amoudi, S. N. Abduljauwad, A. Rasheeduzzafar and M. Maslehuddin, "Effect of Chloride and Sulphate Contamination in Soils on Corrosion of Steel and Concrete,” Transportation Research Record No. 1345, Transportation Research Board, Washington DC, 1992, pp. 67-73.

[21] S. Popovics, "Strength and Related Properties of Concrete: A Quantitative Approach,” John Wiley \& Sons, Inc., New York, 1998, p. 122.

[22] M. Maslehuddin and O. S. B. Al-Amoudi, "Corrosion of Reinforcing Steel in Concrete: Its Monitoring and Preventions,” Symposium on Corrosion and Its Control, Preprint, King Saud University, Riyadh, 1992, pp. 80-90.

[23] M. G. Fontana and N. D. Greene, "Corrosion Engineering,” McGraw-Hill Book Co., New York, 1996, pp. 28116.

[24] A. A. Akindahunsi, G. Oboh and A. A. Oshodi, "Effect of Fermenting Cassava with Rhizopus Oryzae on the Chemical Composition of Its Flour and Garri," Rivista Italiana delle Sostanze Grasse, Vol. 7, No. 6, 1999, pp. 437-440.

[25] M. G. Fontana and N. D. Greene, "Corrosion Engineering,” McGraw-Hill, New York, 1978, p. 59.

[26] O. E. Olorunniwo, L. E. Umoru and O. R. Bamigboye, "Sodium Chromate and Diethylene Amine as Corrosion Inhibitors for Mild Steel in Cassava Fluid,” Journal of Applied Science, Vol. 4, No. 6, 2008, pp. 878-882.

[27] R. E. West and W. G. Hime, "Chloride Profiles in Salty Concrete,” Materials Performance, Vol. 5, 1975, pp. 2936.

[28] A. O. James and O. Akaranta, "The Inhibition of Corrosion of Zinc in 2.0 M Hydrochloric Acid Solution with Acetone Extract of Red Onion Skin," African Journal of Pure and Applied Chemistry, Vol. 3, No. 11, 2009, pp. 212-217.

[29] J. Cruz, R. Martinez, J. Genesca and E. Garcia-Ochoa, "Experimental and Theoretical Study of 1-(2-ethylamino)-2 Methylimidazoline as an Inhibitor of Carbon Steel Corrosion in Acid Media,” Journal of Electroanalytical Chemistry, Vol. 566, No. 1, 2004, pp. 111-121. http://dx.doi.org/10.1016/j.jelechem.2003.11.018

[30] N. Hackerman and E. S. Snavely, "Corrosion Basics: An Introduction,” NACE, Houston, TX, 1984, pp. 127-146. 